\title{
Quantification of gas-accessible microporosity in metal-organic framework glasses
}

Louis Frentzel-Beyme, Pascal Kolodzeiski, Jan-Benedikt Weiß, Sebastian Henke*

Anorganische Chemie, Fakultät für Chemie \& Chemische Biologie, Technische Universität Dortmund, Otto-Hahn Straße 6, 44227 Dortmund, Germany

Email: sebastian.henke@tu-dortmund.de

\begin{abstract}
Metal-organic framework (MOF) glasses are a new class of microporous glass materials with immense potential for applications ranging from gas separation to optics and solid electrolytes. Due to the inherent difficulty to determine the atomistic structure of amorphous glasses, the intrinsic structural porosity of MOF glasses is only poorly understood. In this work, the porosity features of a series of prototypical MOF glass formers from the family of zeolitic imidazolate frameworks (ZIFs) and their corresponding glasses is investigated comprehensively. $\mathrm{CO}_{2}$ gas sorption at $195 \mathrm{~K}$ allows to follow the evolution of microporosity when transforming from the crystalline to the glassy state of these materials. Based on these data, the pore volume and the real density of the ZIF glasses is quantified for the first time. Additional hydrocarbon sorption data ( $n$-butane, propane and propylene) together with X-ray total scattering experiments prove that the porosity features (in particular the pore size and the pore limiting diameter) of the ZIF glasses depend on the types of organic linkers present in the glass network. This allows formulating first design principles for a targeted tuning of the intrinsic microporosity of MOF glasses. Importantly, these principles are counterintuitive and contrary to established porosity design concepts for crystalline MOFs but show similarities to strategies previously developed for porous polymers.
\end{abstract}




\section{Introduction}

Metal-organic frameworks (MOFs) are permanently porous crystalline materials with well-defined ordered structures, which can be precisely designed by a number of advanced synthetic concepts. ${ }^{1-4}$ In the past two decades, MOFs have grown to a class of modular materials with widely tuneable properties for applications ranging from gas separation and storage to sensing, drug delivery and catalysis. ${ }^{5-9}$ MOFs have also been proposed for applications in fields less common for porous materials, such as solid electrolytes and (opto)electronics. ${ }^{10,11}$ In recent years defective, disordered and amorphous MOFs have gained more and more attention since these materials provide access to new and unusual properties beyond the state of the art. ${ }^{12-20}$ Especially solidto-liquid transitions of MOFs are exciting, as they offer processing and shaping of the framework materials in their liquid state (i.e. above their melting temperature, $T_{\mathrm{m}}$ ) and vitrification to a MOF glass after cooling below their glass transition temperature $\left(T_{g}\right) .{ }^{21-}$ ${ }^{25}$ MOF glasses propose unique opportunities for solid state ion conduction ${ }^{20,26,27}$ and gas separation membranes ${ }^{28-30}$ because of improved performance as a result of their monolithic structure and the absence of mass transport limiting grain boundaries. ${ }^{31}$ However, compared to their structurally well-defined crystalline parent materials, it is extremely difficult to predict and design the functionally relevant porosity features (pore volume and pore size) of the MOF glasses. This is due to their highly disordered structure lacking any long-range order, thus precluding atomistic structure determination. ${ }^{32}$ Knowledge of the atomistic structure of porous framework materials, however, is the foundation of materials design along the principles of reticular chemistry. ${ }^{33}$

Zeolitic imidazolate frameworks (ZIFs) are the best investigated family of meltable and glass forming MOFs. ZIFs are composed of tetrahedrally coordinated metal ions (typically $\mathrm{Zn}^{2+}$ or $\mathrm{Co}^{2+}$ ), which are interconnected by imidazolate linkers to form crystalline frameworks exhibiting strong structural similarities to inorganic zeolites..$^{34,35}$ Even though more than 250 crystalline ZIFs featuring $>50$ different topologies have been reported thus far, ${ }^{36}$ just very few of these have been demonstrated to melt and form glasses via melt-quenching. The reported ZIF glass formers include frameworks with cag (ZIF-4, ZIF-62, TIF-4, ZIF-UC-1 to ZIF-UC-5), zni (ZIF-zni) and gis (denoted $\mathrm{Zn}(\mathrm{im})_{2}(\mathrm{GIS})$ ) topologies. ${ }^{23,37-39}$ Meltable ZIFs of these topologies have further been shown to act as a flux for the melting of other ZIF structure types that are non-meltable 
on their own (i.e. ZIF-76, Ita topology; ZIF-8, sod topology). ${ }^{40-42}$ Given that the crystalline ZIF precursors are typically microporous solids with porosity features interesting for gas storage and separation, ${ }^{43-47}$ their melt-quenched glasses are deemed to exhibit similar potential for gas adsorption and separation processes. ${ }^{28,29}$ Nevertheless, gas-accessible microporosity in MOF glasses has been only poorly investigated and was just demonstrated for ZIF glasses obtained from ZIFs with cag topology. ${ }^{30,37,38}$ A quantification of the total gas-accessible pore volume of the ZIF glasses as well as a comprehensive comparison of the porosity of the glasses in relation to their crystalline precursors has not yet been reported.

The prototypical MOF glass former is ZIF-4. During thermal treatment crystalline ZIF4 first collapses to the amorphous phase aTZIF-4 (ат denotes thermally amorphized) at around $315^{\circ} \mathrm{C}$, followed by recrystallization to a denser polymorph of zni topology at approximately $460^{\circ} \mathrm{C}$ (this phase is denoted by zniтZIF-4 here, i.e. thermally recrystallized ZIF-4 with zni topology) and finally melting at about $580{ }^{\circ} \mathrm{C}$ (Fig. 1). ${ }^{21}$ Quenching the ZIF-4 melt to room temperature generates a glass named $a_{g} Z I F-4\left(a_{g}\right.$ denotes amorphous glass). ${ }^{23,48}$ Positron annihilation lifetime spectroscopy (PALS) revealed that $\mathrm{a}_{\mathrm{g}}$ ZIF-4 possesses residual microporosity ${ }^{49}$; a finding supported by highlevel molecular dynamics simulations. ${ }^{50,51}$ Thereon, PALS has been employed to investigate the porosity of other MOF glasses. ${ }^{28,40,52,53}$ However, PALS is unable to prove that the detected pores in the ZIF glasses are in fact accessible to gas molecules, i.e. that the glasses possess an open framework. ${ }^{49}$ Moreover, it is very difficult to quantify porosity (i.e. to determine the specific pore volume of the solid) via this method. ${ }^{54}$

Isothermal $\mathrm{N}_{2}$ physisorption at $77 \mathrm{~K}$ is the gold standard for the quantification of porosity and surface area of crystalline as well as amorphous porous materials. ${ }^{55}$ For a variety of technologically relevant amorphous porous materials (e.g. amorphous silica and amorphous carbons) cryogenic $\mathrm{N}_{2}$ sorption was successfully applied to get valuable insights into the porosity and thus the structure of these materials. ${ }^{56}$ Unfortunately, at $77 \mathrm{~K} \mathrm{~N}_{2}$ is not adsorbed in any ZIF glass investigated so far (i.e. $a_{g}$ ZIF-4, $a_{g}$ ZIF-62 and $a_{g}$ ZIF-UC-2 to $a_{g}$ ZIF-UC-5), ${ }^{21,30,38}$ a phenomenon ascribed to diffusion limitations of $\mathrm{N}_{2}$ gas into the narrow pores of the ZIF glasses at this low temperature. ${ }^{38,57}$ Microporosity for some mixed-linker ZIF glasses was nevertheless demonstrated with $\mathrm{CO}_{2}$ physisorption measurements at $273 \mathrm{~K}$ or $298 \mathrm{~K}$ with a 
maximum $\mathrm{CO}_{2}$ pressure of about $95 \mathrm{kPa}$ (Tab. S6). Even though such kind of measurements provide an experimental proof for gas-accessible microporosity in these ZIF glasses, they do not allow quantification of the major parameter of porosity, namely the pore volume. This is because the sorption data are collected too far away from saturation (note, $\mathrm{a} \mathrm{CO}_{2}$ gas pressure of $100 \mathrm{kPa}$ is equal to only about $0.03 \mathrm{p} / \mathrm{p}_{0}$ at $\left.273 \mathrm{~K}^{57}\right) .58$

a

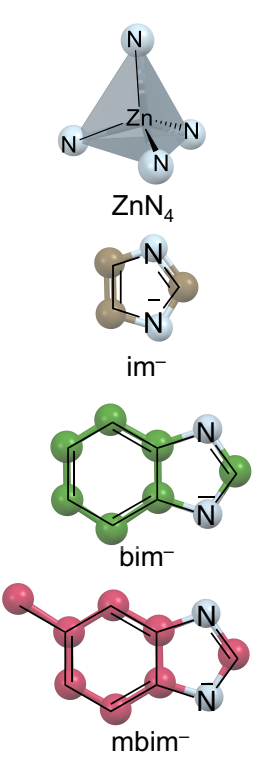

b

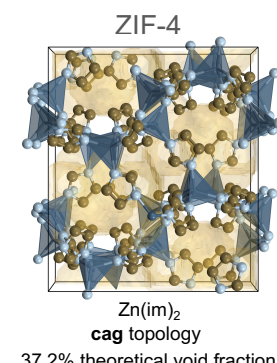
$37.2 \%$ theoretical void fraction ZIF-62

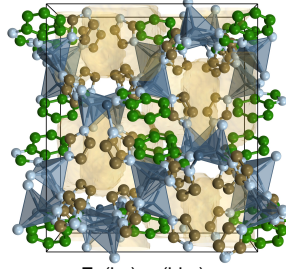

$\mathrm{Zn}(\mathrm{im})_{1.65}(\mathrm{bim})_{0.35}$ cag topology $29.4 \%$ theoretical void fraction $\quad 28.5 \%$ theoretical void fraction
C

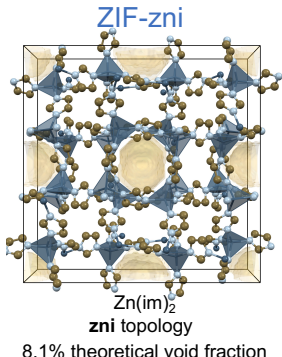
TIF-4

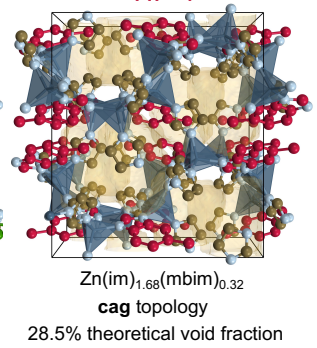

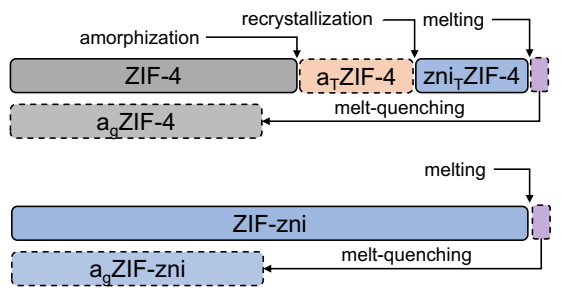

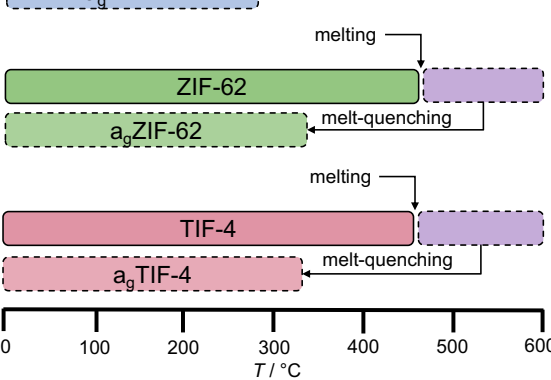

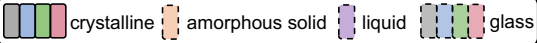

Figure 1. Structural representations and high temperature phase behaviour of the investigated ZIF glass formers. a Building units of the investigated ZIF glass formers. $\mathbf{b}$ Crystal structures of the ZIF glass formers. ZIF-4 (CCDC code IMIDZB11), ZIF-62 (CCDC code SIWJAM) and TIF-4 (CCDC code QOSYAZ) viewed along the crystallographic $b$ axis. ZIF-zni (CCDC code IMIDZB) viewed along the crystallographic $c$ axis. Hydrogen atoms are omitted for clarity. The theoretical void fraction was calculated with a probe radius of $1.3 \AA$ (see Supporting Information $\mathbf{8} 8.4$ for further details) and is shown in pale yellow. $\mathbf{c}$ Schematic representation of the high temperature phase behaviour of the ZIF glass formers.

The present work demonstrates that $\mathrm{CO}_{2}$ gas sorption measurements at $195 \mathrm{~K}$ together with various hydrocarbon sorption measurements provide deep insights into the intrinsic porosity (pore volume and pore size) of ZIF glasses. Based on the low temperature $\mathrm{CO}_{2}$ sorption data, we quantify the specific pore volume of the ZIF glasses for the first time and set it in relation to the porosity of their crystalline framework precursors. In addition to the canonical glass formers ZIF-4 and ZIF-zni (composition $\mathrm{Zn}(\mathrm{im})_{2}$ for both; $\mathrm{im}^{-}=$imidazolate), the mixed-linker glass forming frameworks ZIF-62

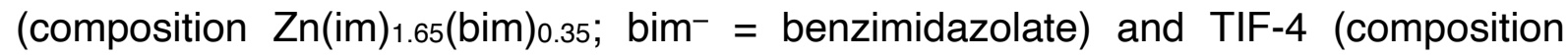
$\mathrm{Zn}(\mathrm{im})_{1.68}(\mathrm{mbim})_{0.32} ; \mathrm{mbim}^{-}=5$-methylbenzimidazolate) are also studied. The latter two featuring a secondary bulky imidazolate linker besides the simple im- linker (Fig. 1). ZIF-4 is particularly interesting due to the series of reconstructive crystalline-to- 
amorphous-to-crystalline phase transitions (ZIF-4 to aTZIF-4 to zniTZIF-4) before melting at approximately $580^{\circ} \mathrm{C}$ (Fig. 1C). The derived specific pore volumes of the ZIF glasses are directly connected to the material's real density, i.e. the density including the intrinsic microporosity, sometimes also referred to as apparent density. ${ }^{59}$ The real density is a fundamental physical parameter, so far poorly investigated for ZIF glasses. Previous studies utilizing $\mathrm{He}$ pycnometry ${ }^{23,38,42}$ could only determine the skeletal density of the glasses (that is the density excluding the intrinsic microporosity). Similarly, density measurements based on Archimedes' principle with potentially pore filling fluids (i.e. ethanol) are expected to yield skeletal densities. ${ }^{60,61}$ Determination of the real density of the glasses by considering the intrinsic micropore volume permits deeper insights into the thermodynamics of melting and glass formation of these new family of glass formers. Combining the low temperature $\mathrm{CO}_{2}$ sorption data with additional hydrocarbon sorption experiments and structural insights derived from X-ray total scattering experiments, allows deducing important correlations of the chemical composition of the ZIF glass former (i.e. single linker or mixed-linker materials) with the pore volume and the pore size of the derived MOF glass. Unexpectedly and most importantly, the relationship between the steric bulk of the linkers and the porosity features of the glasses is counterintuitive and found to be inverse to what is established for crystalline MOFs. The work provides a first guideline for the targeted design of MOF glass porosity by selection of the frameworks' building blocks.

\section{Results}

\section{Materials preparation and characterization}

ZIF-4 (Zn(im)2, cag topology), ZIF-zni $\left(\mathrm{Zn}(\mathrm{im})_{2}, \quad\right.$ zni topology), ZIF-62 ( $\mathrm{Zn}(\mathrm{im})_{1.65}(\mathrm{bim})_{0.35}$, cag topology) and TIF-4 ( $\mathrm{Zn}(\mathrm{im})_{1.68}(\mathrm{mbim})_{0.32}$, cag topology) were synthesized solvothermally reproducing or adapting established procedures. ${ }^{30}$ Solvent molecules were removed from the materials at $200{ }^{\circ} \mathrm{C}$ under dynamic vacuum yielding the activated (solvent-free) compounds. Phase purity of the crystalline ZIFs was verified by structureless profile fits (Pawley method ${ }^{62}$ ) of X-ray powder diffraction (XRPD) patterns using reference data from the literature (Fig. S1-S5). ${ }^{45,63-65}$ The complete removal of solvents from the pores is demonstrated by ${ }^{1} \mathrm{H}$ nuclear magnetic resonance (NMR) and Fourier-transform infrared (FTIR) spectroscopy data (see Supporting Information Section 2 and 3 for further details). ${ }^{1} \mathrm{H}$ NMR spectroscopy was 
further used to determine the linker ratio of the ZIF-62 and TIF-4 samples, leading to the chemical compositions given above (Fig. S28 and S30).

Based on the four crystalline reference materials, the corresponding thermal products (aTZIF-4, zniтZIF-4, agZIF-4, agZIF-zni, $a_{g} Z I F-62$ and $a_{g}$ TIF-4, Fig. 1c) were obtained via thermal treatment under inert atmosphere in a thermogravimetric analysis / differential scanning calorimetry (TGA/DSC) apparatus. DSC data were used as a guide to pick the right temperature protocol to obtain the glasses, as well as the intermediate compounds aTZIF-4 and zniтZIF-4 in the case of ZIF-4 (Fig. 2a, Tab. S2). Heating and cooling rates have been $+10^{\circ} \mathrm{C} \min ^{-1}$ and $-10^{\circ} \mathrm{C} \mathrm{min}-1$, respectively. The temperature profiles and corresponding TGA/DSC data yielding the corresponding products are summarized in the Supporting Information (Tab. S4, Fig. S26-S31). We note, that for the preparation of $a_{g}$ ZIF-4 and $a_{g}$ ZIF-zni an isothermal segment (10 min) at a maximum temperature of $578{ }^{\circ} \mathrm{C}$ was required to obtain amorphous glasses without crystalline residues of ZIF-zni (Fig. S11).

All products were characterized with XRPD and X-ray total scattering, ${ }^{1} \mathrm{H}$ NMR and FTIR spectroscopy, as well as DSC, and the obtained data are in agreement with the literature. ${ }^{21,23,30,39,52,65,66}$ XRPD data of the amorphous materials show only diffuse scattering and no sharp Bragg peaks (Fig. 2b, Fig. S6-S10). A profile fit to the XRPD pattern of zniדZIF-4 testifies the recrystallisation of $a_{\top} Z I F-4$ to the $\mathrm{Zn}(\mathrm{im})_{2}$ phase with zni topology (Fig. S3). The glasses $a_{g} Z I F-4, a_{g} Z I F-z n i, a_{g} Z I F-62$ and $a_{g}$ TIF-4 further possess a fused monolithic structure characteristic for melt-quenched glasses (Fig. S32-S35). It is noteworthy that ${ }^{1} \mathrm{H}$ NMR data of digested ZIF samples demonstrate the full integrity of the organic linkers after thermal treatment, except for $a_{g} Z I F-4$ and $a_{g} Z I F-$ zni (Fig. 2c, S17, S19, S21, S23). For the latter glasses, weak signals for impurities are visible in their ${ }^{1} \mathrm{H}$ NMR spectra. These impurities are ascribed to the presence of some decomposition products which are a consequence of the higher maximum processing temperature $\left(578{ }^{\circ} \mathrm{C}\right)$ of these two glass materials compared to $\mathrm{ag}_{\mathrm{g}} \mathrm{ZIF}-62$ and $\mathrm{ag}_{\mathrm{g}}$ TIF-4 (maximum processing temperature is $475^{\circ} \mathrm{C}$ for those glasses). Partial decomposition of $a_{g} Z I F-4$ and $a_{g}$ ZIF-zni is further indicated by weak scattering signals ascribed to crystalline $\mathrm{ZnO}$ impurities in their X-ray total scattering functions $S(Q)$ (Fig. $2 \mathrm{~d}, \mathrm{~S} 40, \mathrm{~S} 42)$, mass losses of about $6 \%$ during glass preparation in the TGA/DSC experiment (Fig. S28, S29), as well as the dark colour of these glasses (Fig. S32, S33). 
The other three amorphous materials ( $a_{T}$ ZIF-4, $a_{g}$ ZIF-62 and $a_{g}$ TIF-4) show neither signs of decomposition of the organic linkers nor formation of crystalline by-products.
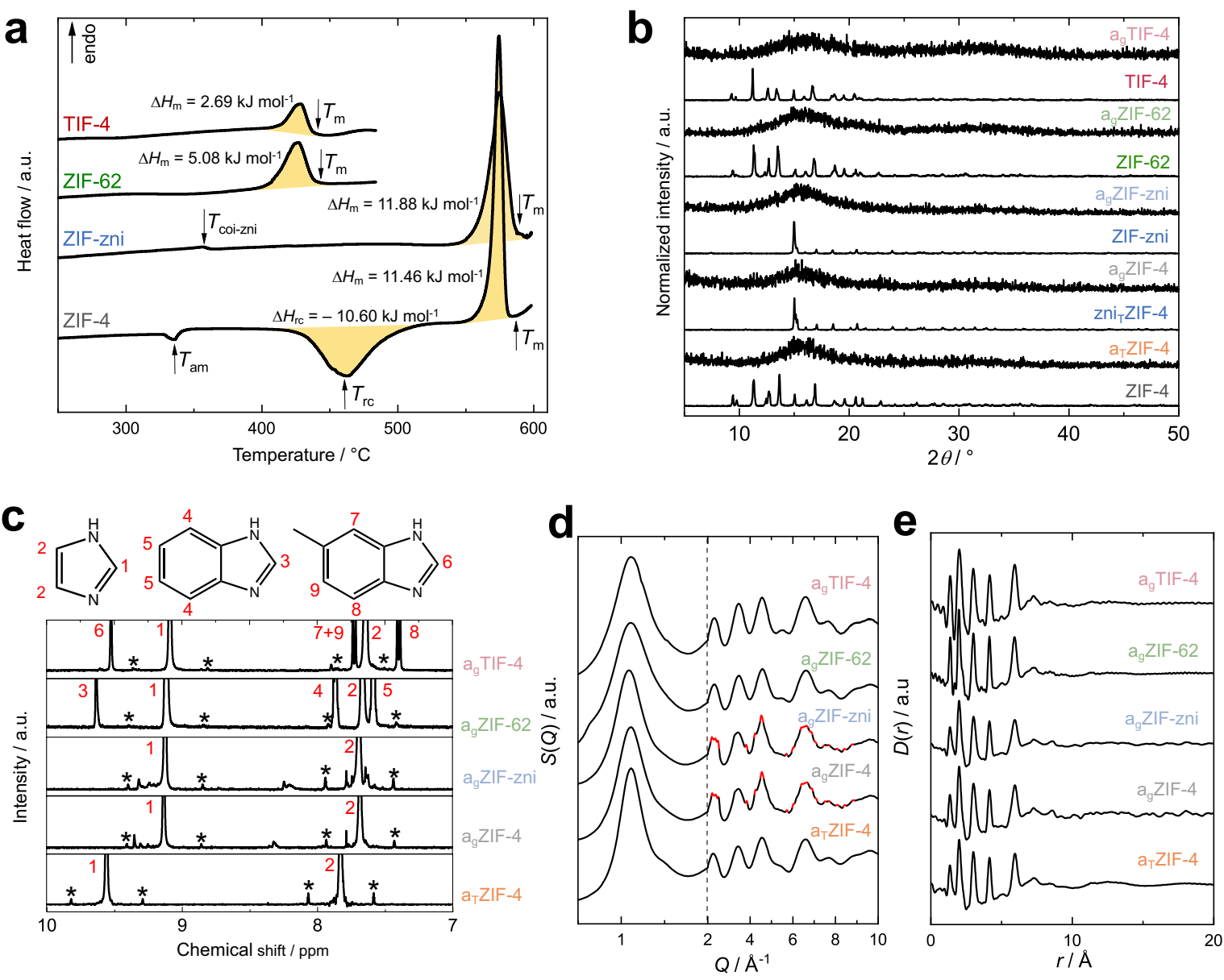

Figure 2. Thermal and structural characterization of the ZIF glass formers and their corresponding glasses. a DSC data of the ZIF glass formers. We note that the DSC curve for ZIF-zni shows a weak endothermic signal at $357^{\circ} \mathrm{C}$ ( $\left.T_{\text {coi-zni) }}\right)$ that is ascribed to the literature known phase transition of a minor impurity of another $\mathrm{Zn}(\mathrm{im}) 2$ polymorph with coi topology (ZIF-coi) to ZIF-zni67 (see Supporting Information S4.1 for further details). b XRPD patterns of all investigated materials. The patterns are vertically offset for clarity. $\mathbf{c}$ Stacked plot of ${ }^{1} \mathrm{H}$ NMR spectra of digested samples of the investigated amorphous materials. A zoom in the aromatic region is shown. The ${ }^{13} \mathrm{C}$ satellite peaks are marked with asterisks $\left(^{*}\right)$. Weak signals not marked with asterisks belong to decomposition products. d X-ray total scattering data in the form $S(Q)$ of the amorphous phases. For $a_{g} Z I F-4$ and $a_{g} Z I F-z n i$ sharp scattering features ascribed to $\mathrm{ZnO}$ impurities are highlighted in red. e XPDFs in the form $D(r)$ obtained from the $S(Q)$ data shown in $\mathbf{d}$. Data for $\mathrm{a}_{\mathrm{g}}$ ZIF-62 in panel $\mathbf{d}$ and $\mathbf{e}$ are taken from ref. ${ }^{30}$.

X-ray pair distribution functions (XPDFs) in the form of $D(r)$ derived via Fouriertransformation of the total scattering functions $S(Q)^{68}$ of all crystalline ZIFs and their thermal products demonstrate that the short-range structure of the crystalline phases (that is $\mathrm{Zn}^{2+}$ ions surrounded by four imidazolate-type linkers) is preserved in all amorphous phases (Fig. 2d and 2e, see Supporting Information Section 7 and Fig. S40, S41). The last sharp peak in the XPDFs of the amorphous materials is visible at 
about $5.9 \AA$ and corresponds to the distance of two neighbouring $\mathrm{Zn}^{2+}$ ions in the networks. The XPDFs of $a_{T} Z I F-4, a_{g} Z I F-62$ and $a_{g}$ TIF-4 show some weaker correlations for $r>5.9 \AA$, which are indicative of some medium range order (MRO). At $r>15 \AA, D(r)$ of these materials converges towards zero. In contrast, the XPDFs of $a_{g} Z I F-4$ and $a_{g} Z I F-z n i$ show additional weak but significant pair correlations extending well beyond $r=20 \AA$ (Fig. S41). These correlations are ascribed to the crystalline ZnO impurities present in these ZIF glasses (Fig. S42).

With the aim to get more insights into the structure of the amorphous ZIF derivatives, we take a closer look at the first sharp diffraction peak (FSDP) of their scattering functions $S(Q)$ (Fig. 2d). The FSDP contains valuable information about the MRO of amorphous network solids. ${ }^{69-71}$ For the ZIF glasses, MRO means some degrees of order extending beyond the first $\mathrm{Zn}-\mathrm{Zn}$ neighbour distance. The position of the FSDP ( $Q_{F S D P}$ ) has been associated with a real space correlation length between the strongest scattering centres (i.e. $\mathrm{Zn}^{2+}$ cations here), which are surrounded by interstitial voids. $^{72,73}$ As such, QFSDP could be regarded as a reciprocal space signature for the glass networks' porosity and density. The full width at half maximum of the FSDP $\left(\triangle Q_{F S D P}\right)$ is inversely proportional to the real space coherence length over which the MRO (i.e. the correlation) exists. ${ }^{72,73}$ We fitted the FSDP of the five amorphous materials under study here to a pseudo-Voigt function to derive $Q_{F S D P}$ and $\Delta Q_{F S D P}$ (see Supporting Information Section 7.1). QFSDP is identical for all solids found at about 1.11 $\AA^{-1}$, suggesting the densities of aTZIF-4 and the four glasses are similar. Remarkably, $\Delta Q_{F S D P}$ is significantly larger for $\mathrm{ag}_{\mathrm{g}} \mathrm{ZIF}-62$ and $\mathrm{a}_{\mathrm{g}} \mathrm{TIF}-4\left(\Delta Q_{\mathrm{FSDP}}=0.35 \AA^{-1}\right)$ than for the amorphous ZIF-4/ZIF-zni derivatives ( $\left.\triangle Q_{F S D P}=0.24-0.29 \AA^{-1}\right)$. This translates to a shorter coherence length for the MRO in the mixed-linker ZIF glasses. Hence, $a_{g} Z I F-$ 62 and $\mathrm{ag}_{\mathrm{g}} \mathrm{TIF}-4$ are more disordered than the single-linker materials, which can be explained by their more complex chemical composition involving two different imidazolate-type linkers with different steric bulk.

\section{$\mathrm{N}_{2}$ physisorption studies}

$\mathrm{N}_{2}$ sorption isotherms at $77 \mathrm{~K}$ were collected for all crystalline and amorphous materials (see Supplementary Information S8). Only crystalline ZIF-4 (the most porous ZIF under study here) adsorbs large amounts of $\mathrm{N}_{2}$, while all other compounds (including crystalline ZIF-62 and TIF-4) show negligible adsorption of $\mathrm{N}_{2}$ at $77 \mathrm{~K}$. These 
observations are in accordance with available $\mathrm{N}_{2}$ sorption data of ZIF glasses and point towards strong $\mathrm{N}_{2}$ diffusion limitations at $77 \mathrm{~K}$ due to the narrow pores of these ZIFs. ${ }^{14,21,30}$ Hence, the pore volume of the ZIF glasses cannot be probed by $\mathrm{N}_{2}$ sorption.

\section{$\mathrm{CO}_{2}$ physisorption studies and pore volume determination}

In order to get around the gas diffusion limitations, the porosity of all materials was probed by $\mathrm{CO}_{2}$ physisorption at $195 \mathrm{~K}$. The smaller kinetic diameter of the $\mathrm{CO}_{2}$ molecule $\left(3.3 \AA^{74}\right)$ compared to $\mathrm{N}_{2}\left(3.6 \AA^{74}\right)$ together with the higher temperature ( $195 \mathrm{~K}$ vs. $77 \mathrm{~K}$ ) facilitates the diffusion of the gas into very small micropores (< $5 \AA$ A). ${ }^{75,76}$ Compared to the $\mathrm{CO}_{2}$ sorption experiments performed at $273 \mathrm{~K}$ or $298 \mathrm{~K}$, running the experiment at $195 \mathrm{~K}$ allows reaching saturation (i.e. $p / p_{0} \rightarrow 1$ ) at ambient pressure. Consequently, the determined gas capacities $\left(n_{\mathrm{ads}}^{\max }\right)$ at the maximum collected pressure $\left(p \approx 95 \mathrm{kPa}, p / p_{0} \approx 0.95\right)$ allow to determine the specific pore volume ( $\left.V_{\text {pore }}\right)$ of the investigated materials by making the established assumption that the adsorbate fills the entire pore space at this pressure ${ }^{77}$ (Tab. 1, Fig. 3, see Supporting Information S8.2 for further details). Brunauer-Emmett-Teller (BET) specific surface areas ${ }^{78}$ have also been determined from the low temperature $\mathrm{CO}_{2}$ sorption isotherms (Tab. 1, see Supporting Information S8.2 for further details). Even though utilization of the BET model is very common in research on porous materials, we note that BET surface areas determined from $\mathrm{CO}_{2}$ sorption data recorded at $195 \mathrm{~K}$ are typically much lower than values determined via $\mathrm{N}_{2}$ sorption at $77 \mathrm{~K} .{ }^{58}$ In general, the BET model is not applicable for the microporous materials studied here. ${ }^{57}$ Thus, we provide these data only for reference.

We first concentrate on ZIF-4, ZIF-zni and their corresponding amorphous and crystalline high temperature phases. Remarkably, all these phases adsorb $\mathrm{CO}_{2}$ as evident from the Typ I (or Langmuir) shaped isotherms (Fig. 3a). As expected, the crystalline ZIF-4 exhibits the highest $V_{\text {pore }}$ of $0.31 \mathrm{~cm}^{3} \mathrm{~g}^{-1}$ (Tab. 1). Going along the other ZIF-4 phases consecutively formed via thermal treatment, we first see a drastic decrease in $V_{\text {pore }}$ to $0.11 \mathrm{~cm}^{3} \mathrm{~g}^{-1}$ for aTZIF-4 (-65\% compared to ZIF-4), demonstrating a collapse and densification of the framework but preservation of about $35 \%$ of the pore space of the crystalline phase. $V_{\text {pore }}$ drops further for the recrystallized zniтZIF-4 $\left(V_{\text {pore }}=0.05 \mathrm{~cm}^{3} \mathrm{~g}^{-1}\right)$ to only about $16 \%$ of the porosity of crystalline ZIF-4. Noteworthy, 
the solvothermally synthesized ZIF-zni features the same pore volume ( $V_{\text {pore }}=$ $0.05 \mathrm{~cm}^{3} \mathrm{~g}^{-1}$ ) as zniтZIF-4, establishing that $a_{T} Z I F-4$ completely recrystallizes to zniTZIF-4 during thermal treatment. This is in line with the very similar melting enthalpies $\left(\Delta H_{\text {melt }}\right)$ for zniTZIF-4 $\left(11.46 \mathrm{~kJ} \mathrm{~mol}^{-1}\right)$ and ZIF-zni $\left(11.88 \mathrm{~kJ} \mathrm{~mol}^{-1}\right)$ determined via DSC (Fig. 2a and Tab. S3). Since ZIF-zni, which is the densest and most stable $\mathrm{Zn}(\mathrm{im})_{2}$ phase (at least at temperatures $>360{ }^{\circ} \mathrm{C}^{67}$ ), is already microporous, it is not surprising that $\mathrm{ag}_{\mathrm{g}} \mathrm{ZIF}-4$ and $\mathrm{ag}_{\mathrm{g}} \mathrm{ZIF}-\mathrm{zni}$ also adsorb $\mathrm{CO}_{2}$. Both glasses show very similar $\mathrm{CO}_{2}$ sorption isotherms with specific pore volumes of $0.12 \mathrm{~cm}^{3} \mathrm{~g}^{-1}$ and $0.13 \mathrm{~cm}^{3} \mathrm{~g}^{-1}$, respectively.

a

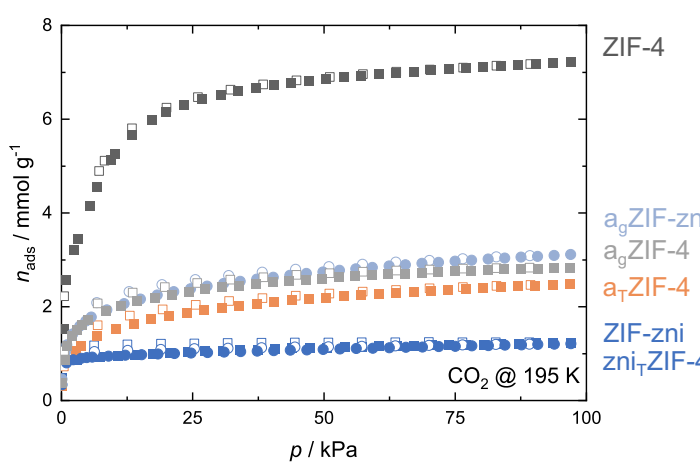

C

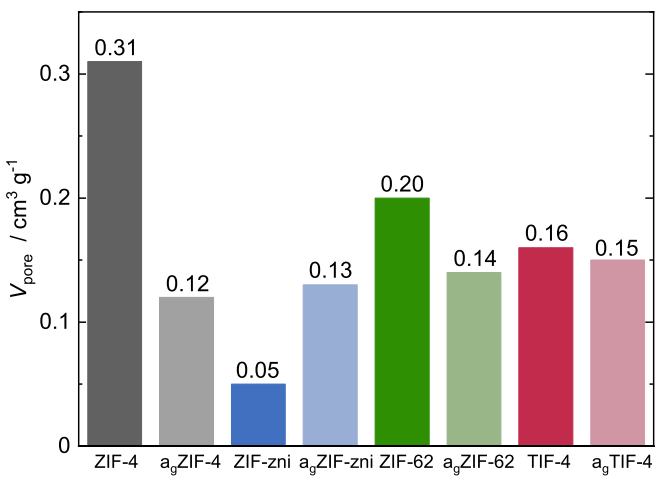

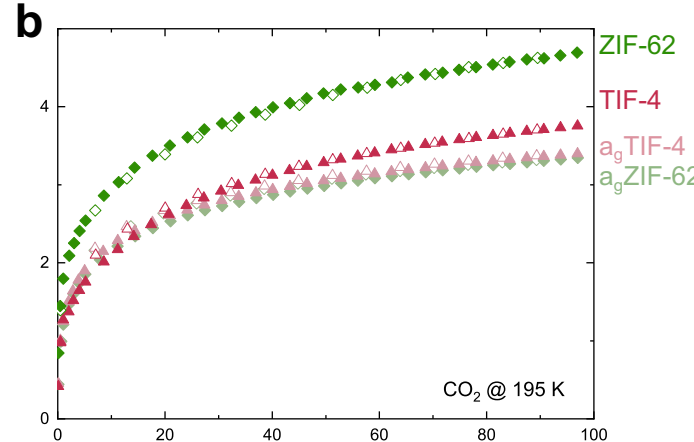

d

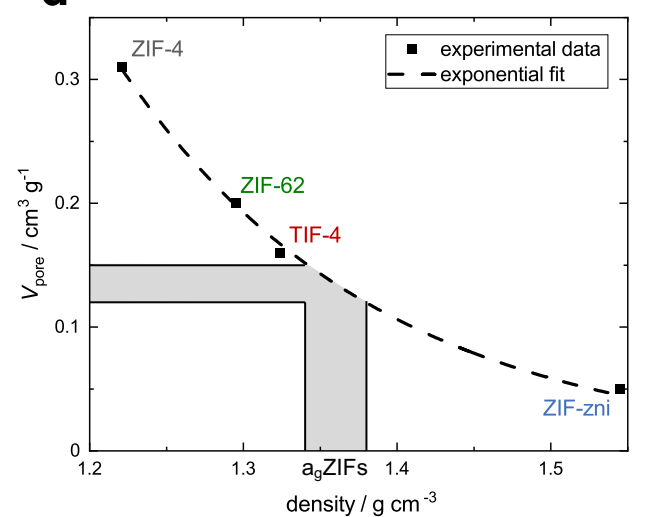

Figure 3. $\mathrm{CO}_{2}$ gas sorption analysis. a $\mathrm{CO}_{2}$ sorption isotherms collected at $195 \mathrm{~K}$ of ZIF-4 and ZIF-zni and their corresponding thermal products. ZIF-4 derivatives are shown as squares. ZIF-zni derivatives are shown as circles. b $\mathrm{CO}_{2}$ isotherms collected at $195 \mathrm{~K}$ of ZIF-62 and TIF-4 and their corresponding glasses. ZIF-62 derivatives are shown as rhombs. TIF-4 derivatives are shown as triangles. In panel $\mathbf{a}$ and $\mathbf{b}$ adsorption and desorption branches are shown as closed and open symbols, respectively. $\mathbf{c}$ Bar plot of total pore volumes ( $V_{\text {pore }}$ ) for all crystalline ZIFs and their corresponding glasses derived from the $\mathrm{CO}_{2}$ isotherms at $195 \mathrm{~K}$. d Plot of density against $V_{\text {pore }}$ of all crystalline ZIFs with exponential fit. The ZIF glass bulk densities can be estimated based on their experimentally obtained $V_{\text {pore }}$ (see light grey area). 
Table 1. Summary of maximum gas capacities $\left(\boldsymbol{n}_{\mathrm{ads}}^{\max }\right)$, specific pore volumes ( $\left.V_{\text {pore}}\right)$ and BET surface area $\left(S_{\mathrm{BET}}\right)$ obtained from the $\mathrm{CO}_{2}$ gas physisorption isotherms collected at $195 \mathrm{~K}$ together with respective densities $(\boldsymbol{\rho})$ for all investigated materials.

\begin{tabular}{ccccc}
\hline compound & $\begin{array}{c}n_{\mathrm{ads}}^{\max } \\
{\left[\mathrm{mmol} \mathrm{g}^{-1}\right]}\end{array}$ & $\begin{array}{c}V_{\text {pore }} \\
{\left[\mathrm{cm}^{3} \mathrm{~g}^{-1}\right]}\end{array}$ & $\begin{array}{c}S_{\mathrm{BET}} \\
{\left[\mathrm{m}^{2} \mathrm{~g}^{-1}\right]}\end{array}$ & $\begin{array}{c}\rho \\
{\left[\mathrm{g} \mathrm{cm}^{-3}\right]}\end{array}$ \\
\hline ZIF-4 & 7.22 & 0.31 & 473 & $1.22^{\mathrm{a}}$ \\
$\mathrm{a}_{\mathrm{T}}$ ZIF-4 & 2.49 & 0.11 & 140 & $1.39^{\mathrm{b}}$ \\
zni $\mathrm{T}$ ZIF-4 & 1.23 & 0.05 & 89 & $1.56^{\mathrm{a}}$ \\
$\mathrm{a}_{\mathrm{g}}$ ZIF-4 & 2.84 & 0.12 & 186 & $1.38^{\mathrm{b}}$ \\
ZIF-zni & 1.21 & 0.05 & 92 & $1.56^{\mathrm{a}}$ \\
$\mathrm{a}_{\mathrm{g}}$ ZIF-zni & 3.12 & 0.13 & 183 & $1.37^{\mathrm{b}}$ \\
ZIF-62 & 4.70 & 0.20 & 257 & $1.29^{\mathrm{a}}$ \\
$\mathrm{a}_{\mathrm{g}}$ ZIF-62 & 3.34 & 0.14 & 194 & $1.35^{\mathrm{b}}$ \\
TIF-4 & 3.76 & 0.16 & 180 & $1.32^{\mathrm{a}}$ \\
$\mathrm{a}_{\mathrm{g}}$ TIF-4 & 3.40 & 0.15 & 199 & $1.34^{\mathrm{b}}$ \\
\hline a crystallographic density. & $\mathrm{b}$ experimental density calculated from CO &
\end{tabular}

${ }^{a}$ crystallographic density. ${ }^{b}$ experimental density calculated from $\mathrm{CO}_{2}$ adsorption data.

The crystalline glass precursors ZIF-4, ZIF-62 and TIF-4 feature the same cag topology. Their pore volumes decrease from $0.31 \mathrm{~cm}^{3} \mathrm{~g}^{-1}$ (ZIF-4) to $0.20 \mathrm{~cm}^{3} \mathrm{~g}^{-1}$ (ZIF62) to $0.16 \mathrm{~cm}^{3} \mathrm{~g}^{-1}$ (TIF-4). This correlates with the implementation of the secondary bulky imidazolate linkers (bim- and $\mathrm{mbim}^{-}$) in ZIF-62 and TIF-4, reducing the void space of the crystalline framework (see void fractions calculated based on the crystal structures shown in Fig. 1b). We note that the concentration of the bim- and $\mathrm{mbim}^{-}$ linkers in the mixed linker MOFs is rather similar (ZIF-62: Zn(im)1.65(bim) 0.35 ; TIF-4: $\mathrm{Zn}(\mathrm{im})_{1.68}(\mathrm{mbim})_{0.32}$ ), while the steric bulk of $\mathrm{mbim}^{-}$(containing an additional methyl group) is higher compared to bim- $^{-}$. This further decreases the free void space in crystalline TIF-4 and explains the higher $V_{\text {pore }}$ of ZIF-62 over TIF-4 (Fig. 3c).

Remarkably, the pore volumes of the mixed-linker glasses $a_{g} Z I F-62$ ( $V_{\text {pore }}=$ $\left.0.14 \mathrm{~cm}^{3} \mathrm{~g}^{-1}\right)$ and $\mathrm{ag}_{\mathrm{g}}$ TIF-4 $\left(V_{\text {pore }}=0.15 \mathrm{~cm}^{3} \mathrm{~g}^{-1}\right)$ are slightly higher than for $\mathrm{a}_{g} Z \mathrm{ZIF}-4$ and agZIF-zni (Fig. 3b, c). This is counterintuitive by comparing the pore volumes of the respective crystalline parent materials. The highest reduction in $V_{\text {pore }}$ (approximately $61 \%$ ) from the crystalline to the glass material is found for ZIF-4, while only a reduction of $30 \%$ and $6 \%$ is found for the glasses of ZIF-62 and TIF-4. This observation suggests 
that $a_{g}$ ZIF-62 and $a_{g}$ TIF-4 have a pore structure which is more similar to that of their crystalline precursors, while $a_{g}$ ZIF-4 differs strongly from crystalline ZIF-4.

It must be noted that the presence of small amounts of decomposition products ( $\mathrm{ZnO}$ and decomposed organic linkers, see above) in $a_{g}$ ZIF-4 and $a_{g}$ ZIF-zni could potentially reduce the specific gas capacities and the corresponding $V_{\text {pore. Nevertheless, the }}$ thermally amorphized phase aTZIF-4, which does not contain any decomposition products, features an even lower pore volume $\left(V_{\text {pore }}=0.11 \mathrm{~cm}^{3} \mathrm{~g}^{-1}\right)$ than $\mathrm{ag}_{\mathrm{g}} \mathrm{ZIF}-4$ and $a_{g}$ ZIF-zni, suggesting that their partial decomposition only has a minor influence on $V_{\text {pore. }}$ Moreover, the finding that $V_{\text {pore }}$ of $a_{\mathrm{T}}$ ZIF-4, $\mathrm{ag}_{\mathrm{g}}$ ZIF-4 and $\mathrm{ag}_{\mathrm{g}} \mathrm{ZIF-zni}$ are similar is in line with our analysis of the FSDP of the scattering function, as well as the previous observation that $a_{T} Z I F-4$ and $a_{g} Z$ IF-4 are located at the same place on the potential energy landscape of $\mathrm{Zn}(\mathrm{im})_{2 .}{ }^{21}$

For comparison we collected additional $\mathrm{CO}_{2}$ sorption isotherms of all materials at $273 \mathrm{~K}$ (Fig. S46, S47). Here, we see again the highest capacity for ZIF-4 (2.64 mmol g-1) followed by ZIF-62 (1.87 mmol g$\left.{ }^{-1}\right)$ and TIF-4 (1.43 mmol g$\left.{ }^{-1}\right)$ whereas the amorphous materials (aTZIF-4, $a_{g}$ ZIF-4, $a_{g}$ ZIF-zni, $a_{g}$ ZIF-62, $a_{g}$ TIF-4) as well as the materials adopting the zni topology (zniтZIF-4, ZIF-zni) show lower uptakes in the range from 0.81-1.21 $\mathrm{mmol} \mathrm{g}^{-1}$ (Tab. S6). As expected, the drastic differences in $V_{\text {pore }}$ of the various ZIF materials are not observable in the $\mathrm{CO}_{2}$ sorption data collected at $273 \mathrm{~K}$, since data are only collected up to about $0.03 \mathrm{p} / \mathrm{p}_{0}$.

In order to get deeper insights into the pore size of the glasses compared to their crystalline precursors, we calculated pore size distributions (PSDs) based on the $\mathrm{CO}_{2}$ sorption data by utilizing the Horvath-Kawazoe $(\mathrm{HK})$ method $^{79}$ (isotherms recorded at $195 \mathrm{~K}$, slit pore model, Fig. S53) or by nonlocal density functional theory (NLDFT) 80 models (isotherms recorded at $273 \mathrm{~K}$, slit pore model, Fig. S54). Importantly, the PSDs of the crystalline ZIF-4 and ZIF-zni derived via both methods are in strong disagreement to the theoretical PSDs calculated from the corresponding crystal structures (calculation performed with Zeo++ ${ }^{81}$, see Supporting Information S8.3 for further details). The HK and NLDFT models both derive a much broader pore size distribution and either significantly overestimate or underestimate the maximum pore diameter in comparison to the results expected from the simulations. Since neither the HK nor the NLDFT method can reproduce the theoretical PSDs of the crystalline ZIFs, we conclude that these models are also inadequate to examine the PSDs of the glassy 
materials under study here. We hope that future statistical models for $\mathrm{CO}_{2}$ gas sorption will be able to safely reproduce the porous features of crystalline ZIFs, so that these models could also be used to shed light on the pore size distribution of ZIF glasses. ${ }^{82}$

\section{Density determination}

The $V_{\text {pore }}$ quantified from the $\mathrm{CO}_{2}$ sorption data recorded at $195 \mathrm{~K}$ allows determination of the real density of the ZIF glasses. As stated above, the real density of porous ZIF glasses is unknown so far, since He pycnometry (the established method for density determination of small volume powder samples) only allows to determine their skeletal density (He penetrates also into the micropores of the materials). ${ }^{83}$ Nevertheless, the real density by also considering the intrinsic micropores of the material is one of the key materials properties not only for technological applications, but also as a boundary condition for computational modelling of such amorphous materials. ${ }^{50,84} \mathrm{Here}$, the real densities of the ZIF glasses are determined according to the following procedure.

At first, we calculated the theoretical void fraction (tVF) for crystalline ZIF-4 and ZIFzni based on their crystal structures (tVFZIF-4 $=37.2 \%$, tVF ZIF-zni $=8.1 \%$; Fig. $1 \mathrm{~b}$ ) and compared these values to the experimental void fraction $\left(\mathrm{eVF}=V_{\text {pore }} \cdot \rho_{\text {cryst }}\right)$ calculated from $V_{\text {pore }}$ and the crystallographic densities ( $\rho_{\text {cryst; }}$; see Supporting Information S8.4 for further details). For both crystalline ZIFs we found a very good agreement between theory and experiment $\left(e V F_{Z I F-4}=37.5 \%\right.$, eVF comparison of the tVFs to the eVFs for crystalline ZIF-62 and TIF-4 is challenging due to disorder of the secondary bulky linkers in their crystal structures.

Subsequently, $V_{\text {pore }}$ of the crystalline ZIF-4, ZIF-zni, ZIF-62 and TIF-4 was plotted against their $\rho_{\text {cryst }}$ (Fig. 3d). The data could be very well fitted with an exponential function ( $R^{2}=0.998$, see Supporting Information Section S8.4 for further details), which then allows to calculate the densities of the glasses from their experimental pore volumes (Table 1). In correspondence to their quite similar $V_{\text {pore, }}$ we find comparable densities for all glasses in the range from $1.34-1.38 \mathrm{~cm}^{3} \mathrm{~g}^{-1}$. Importantly, these densities are up to $20 \%$ lower than the skeletal densities previously determined for ZIF glasses by $\mathrm{He}$ pycnometry. ${ }^{23}$ Additionally, our data suggest that the density values previously obtained via Archimedes' principle are also too high. ${ }^{60,61}$ Here, ethanol was utilized as the soaking solvent which might also penetrate (at least partially) into the glasses' micropores. Based on the pore volumes and densities derived by our method, 
we further estimate an intrinsic void fraction between $17 \%$ and $20 \%$ for the ZIF glasses (see Supplementary Information S8.2 for details).

\section{Hydrocarbon Physisorption Studies}

Since reliable information on the PSDs of the ZIF glasses could not be obtained from the $\mathrm{CO}_{2}$ sorption isotherms, we intended to get deeper insights into their pore sizes via hydrocarbon sorption ( $n$-butane at $273 \mathrm{~K}$, propane and propylene at $293 \mathrm{~K}$, Fig. 4). In

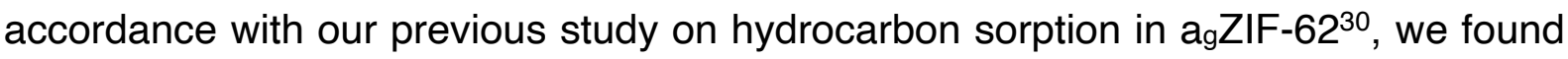
a comparable adsorption of $n$-butane for $a_{g}$ ZIF-62 and $a_{g}$ TIF-4. The isotherms are of Type I shape (Langmuir), typical for adsorption in microporous solids, and feature a strong hysteresis, signifying diffusion limitations of $n$-butane in the narrow pores of the ZIF glasses. Calculation of the void volume occupied by $n$-butane close to saturation $(p \approx 95 \mathrm{kPa})$ and comparison with the void volume determined via $\mathrm{CO}_{2}$ sorption signifies that $n$-butane is only able to access about one third of the void space available in $a_{g}$ ZIF-62 and $a_{g}$ TIF-4 (Tab. S9).

Surprisingly, $a_{g}$ ZIF-4 and $a_{g}$ ZIF-zni do not adsorb any $n$-butane in their pores but only on the external surface, resulting in linearly shaped isotherms. The contrasting sorption properties of $a_{g}$ ZIF-4 and $a_{g}$ ZIF-zni compared to $a_{g}$ ZIF-62 and $a_{g}$ TIF-4 indicate important differences in the pore structure of these glasses. The larger kinetic diameter of $n$-butane $(4.3 \AA)^{74}$ compared to $\mathrm{CO}_{2}(3.3 \AA)^{74}$ signifies that the pore limiting diameter of $a_{g}$ ZIF-4 and $a_{g}$ ZIF-zni is smaller than the one of the glasses featuring a secondary bulky imidazolate linker ( $a_{g}$ ZIF-62 and $a_{g}$ TIF-4). It appears that this difference is not originating from the higher processing temperatures and the slight decomposition of $a_{g}$ ZIF-4 and $a_{g}$ ZIF-zni, since $a_{T}$ ZIF-4 (thermally amorphized at $379{ }^{\circ} \mathrm{C}$, no decomposition) does also only adsorb $n$-butane on its external surface and not in the micropores (Fig. S48). Thus, the presence of a secondary bulky imidazolate linker appears to be a key parameter for the pore size and pore limiting diameter of the ZIF glasses.

In contrast, propane and propylene isotherms at $293 \mathrm{~K}$ feature a Langmuir-shape (typical for adsorption in micropores) and show comparable uptakes for the investigated ZIF glasses (Fig. $4 \mathrm{~b}$ and $\mathrm{c}$, Tab. S7). In accordance with our recent findings, we see a much higher adsorption affinity for propylene over propane ${ }^{30}$ (Fig. 
S50-51). This trend is already present in the crystalline parent materials ZIF-62 and TIF-4 (Fig. S50-51). The fact that $a_{g} Z$ ZIF-4 adsorbs propane and propylene, but not $n$ butane is surprising at first sight, since all three gases have almost identical kinetic diameters $(d)^{74}\left(d_{\text {propane }}=4.3 \AA\right.$, $d_{\text {propylene }}=4.5 \AA$, $\left.d_{n \text {-butane }}=4.3 \AA\right)$. We suspect that the exclusion of $n$-butane from the pores of $a_{T} Z I F-4, a_{g} Z I F-4$ and $a_{g} Z I F-z n i$ is not a consequence of sorption kinetics, but of the significantly larger molecular size of the $n$ butane molecule $\left(V_{\mathrm{mol}} \approx 161 \AA^{3}\right)$ compared to propane $\left(V_{\mathrm{mol}} \approx 126 \AA^{3}\right)$ and propylene $\left(V_{\mathrm{mol}} \approx 115 \AA^{3} ; V_{\mathrm{mol}}\right.$ is the molecular volume of the hydrocarbons considering their densities at the boiling point ${ }^{85-87}$ ). Hence, our sorption data demonstrate that the amorphous networks of the composition Zn(im)2 (i.e. $a_{T} Z I F-4, a_{g} Z I F-4$ and $\left.a_{g} Z I F-z n i\right)$ exhibit narrower pore openings than the network glasses containing a secondary bulky imidazolate linker (i.e. $a_{g}$ ZIF-62 and $a_{g}$ TIF-4).
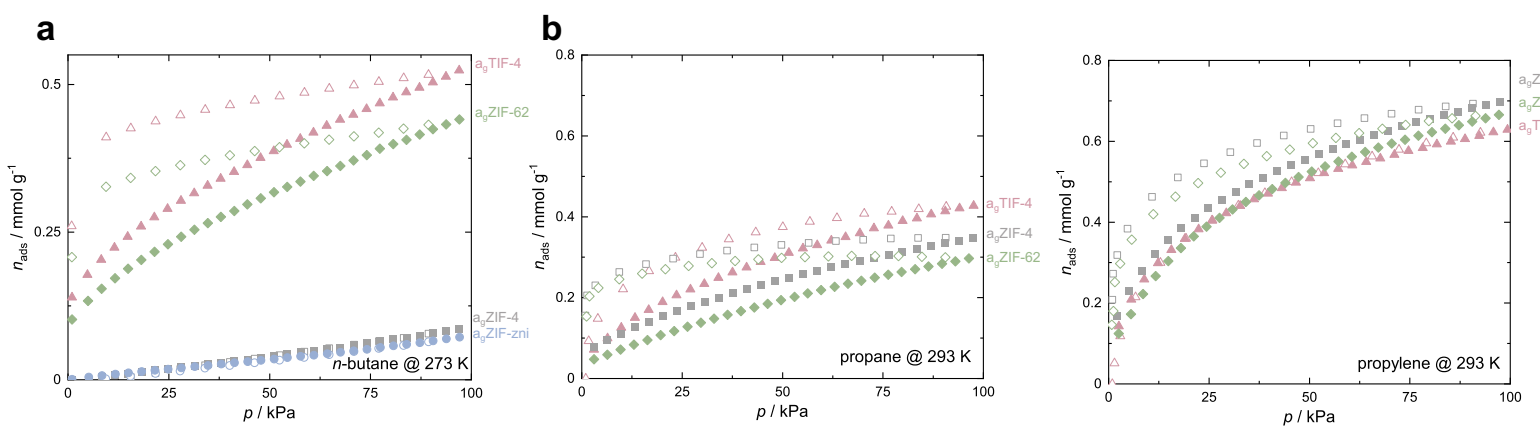

Figure 4. Hydrocarbons sorption studies. a $n$-butane sorption isotherms of the ZIF glasses collected at $273 \mathrm{~K} . \mathbf{b}$ Propane and propylene sorption isotherms collected at $293 \mathrm{~K}$. In all panels, adsorption and desorption branches are shown as closed and open symbols, respectively.

\section{Discussion}

For the first time, we investigated the porosity of a compositional series of ZIF glasses in detail, determined their pore volumes and compared them to their crystalline framework precursors. This series includes ZIF materials containing only the small imlinker (ZIF-4 and ZIF-zni) and others featuring a secondary bulky imidazolate linker (bim- or mbim $^{-}$) next to im- (ZIF-62 and TIF-4). All glasses are found to own $\mathrm{CO}_{2}$ accessible microporosity and specific pore volumes in the range from 0.12 to $0.15 \mathrm{~cm}^{3}$ $\mathrm{g}^{-1}$. This also includes $\mathrm{ag}_{\mathrm{g}} \mathrm{ZIF}-4$ and $\mathrm{a}_{\mathrm{g}} \mathrm{ZIF-zni}$ whose open pore space was so far understood as being inaccessible for gases. ${ }^{21,49}$ We thus conclude that microporosity is an intrinsic feature of the class of ZIF glasses, which is a huge benefit compared to 
conventional inorganic glasses, whose microporosity typically must be generated via elaborate post treatment methods (e.g. leaching procedures). ${ }^{88}$

The specific pore volumes of the ZIF glasses provided a means to calculate the real densities of these glasses. These densities are much lower than the previously reported skeletal densities of ZIF glasses and lie in between the density of the most porous glass former ZIF-4 and its most dense (but still microporous) polymorph ZIFzni. The fact that the density of $\mathrm{a}_{\mathrm{g}}$ ZIF-62 $\left(\rho=1.35 \mathrm{~cm}^{3} \mathrm{~g}^{-1}\right)$ is higher than the density of crystalline ZIF-62 $\left(\rho=1.29 \mathrm{~cm}^{3} \mathrm{~g}^{-1}\right)$ is in accordance with the negative Clapeyron slope behaviour reported for ZIF-62 (i.e. melting point lowering with increasing pressure). ${ }^{89}$ Our data suggest a similar behaviour for TIF-4 $\left(\rho\right.$ (TIF-4) $=1.32 \mathrm{~g} \mathrm{~cm}^{-3}$, $\rho\left(\mathrm{ag}_{\mathrm{g}}\right.$ TIF-4 $\left.)=1.34 \mathrm{~g} \mathrm{~cm}^{-3}\right)$. In turn, the higher density of ZIF-zni $\left(\rho(Z I F-z n i)=1.56 \mathrm{~g} \mathrm{~cm}^{-}\right.$ 3) compared to the corresponding glass $\left(\rho\left(\mathrm{a}_{\mathrm{g}} \mathrm{ZIF}-\mathrm{zni}\right)=1.37 \mathrm{~g} \mathrm{~cm}^{-3}\right)$ suggest a positive slope of the melting curve and thus 'conventional' melting behaviour (i.e. an increasing melting point with increasing pressure). Moreover, ZIF-4 transforms completely to its denser polymorph with zni topology (zniTZIF-4) before melting occurs and thus is also expected to show a positive Clapeyron slope behaviour.

We generally find slightly lower specific pore volumes and slightly higher densities for $a_{g}$ ZIF-4 and $a_{g}$ ZIF-zni compared to the ZIF glasses containing a secondary bulky imidazolate-type linker. This proves the importance of the bulky linker for a less dense packing of the molecular building units in the glass state, ${ }^{15,38,53}$ and is also in line with systematic differences of the glasses' $\Delta Q_{F S D P}$, suggesting lower MRO in the glasses containing two different linkers. The important structural differences of the glasses with and without the secondary bulky linkers are further corroborated by hydrocarbon sorption experiments, showing that $a_{g}$ ZIF-62 and $a_{g}$ TIF-4 adsorb n-butane, while $a_{g}$ ZIF-4 and $a_{g}$ ZIF-zni do not. This is in stark contrast with the porosity features of the corresponding crystalline ZIF phases, where more bulky linkers result in a significant reduction of pore volume and increased steric hindrance for the diffusion of larger molecules.

The present study provides important new insights into the porosity features of MOF glasses and thus contributes to our understanding of the structure of such glasses. Our findings suggest that conventional porosity design principles, as established for crystalline MOFs and crystalline framework materials in general, ${ }^{1,2,33}$ cannot be applied for their glassy state. Rather new design concepts for tuning and adjusting porosity 
and sorption selectivity of MOF glasses must be developed. We envision that principles which have already been established for other amorphous porous materials may be adaptable for MOF glasses. An example are porous polymers, such as polymers with intrinsic microporosity (PIMs), where molecular building blocks, which facilitate inefficient packing of the polymer chains, result in enhanced porosity. ${ }^{90-93}$ Following this route, we propose that via implementation of larger and asymmetric linkers the porosity of MOF glasses is tuneable far beyond the state of the art, opening the door for the development of much more porous MOF glasses with tailored porosity.

\section{Methods}

Materials synthesis. The synthesis routes for ZIF-4 (chemical composition $\left(\mathrm{Zn}(\mathrm{im})_{2}\right)$ and ZIF-62 (chemical composition $\mathrm{Zn}(\mathrm{im}) 1.65$ (bim)0.35) were reproduced as stated in our previous publication. ${ }^{30}$ ZIF-zni was synthesized after a modified solvothermal synthesis route based on ZIF-4 by solely replacing the original solvent $N, N$-dimethylformamide (DMF) with ethanol. TIF-4 (chemical composition: ( $\left.\mathrm{Zn}(\mathrm{im})_{1.68}(\mathrm{mbim}) 0.32\right)$ was synthesized after the same procedure as ZIF-62 by replacing the secondary bulky linker benzimidazole (Hbim) by 5-methylbenzimidazole (Hmbim) in the synthesis. Sample activation was performed at $200^{\circ} \mathrm{C}$ and dynamic vacuum $\left(p \approx 10^{-4} \mathrm{kPa}\right)$ overnight.

Based on the four crystalline materials, their thermal products were obtained via thermal treatment in a TGA/DSC apparatus (see Supporting Information Section 4.2 for further details).

X-ray powder diffraction (XRPD). XRPD patterns were recorded at room temperature on a Siemens D5005 diffractometer in Bragg-Brentano geometry. Data were collected with CuKa radiation in the range from $5^{\circ}$ to $50^{\circ} 2 \theta$ with a step size of $0.02^{\circ}$. Finely ground samples (crystalline or glassy) were deposited on a glass holder or a single crystal zero background sample holder made of silicon (cut along the (610) plane). For phase identification, structureless profile fits (Pawley method ${ }^{62}$ ) were performed with the TOPAS academic v6 software ${ }^{94}$.

Fourier transform infrared (FTIR) spectroscopy was carried out on a Perkin Elmer SpectrumTwo FTIR spectrometer $\left(\tilde{v}=400 \mathrm{~cm}^{-1}-4000 \mathrm{~cm}^{-1}\right)$ in reflection mode using 
a diamond ATR (attenuated total reflectance) unit. Powdered samples were placed on the diamond ATR unit and carefully compressed with a stamp for the measurement.

Scanning electron microscopy (SEM) imaging was performed with a Hitachi S-4500 instrument. For measurements, samples were placed on a conductive adhesive pad. Imaging was done with $1 \mathrm{kV}$ accelerating voltage on a secondary electron detector. All investigated samples were ground and taken from the sorption tubes after conduction of physisorption measurements before imaging.

Nuclear magnetic resonance (NMR) sprectroscopy. Solution ${ }^{1} \mathrm{H}$ NMR spectroscopy was performed on digested crystalline and glassy ZIF samples with Bruker DPX-300, DPX 500 or Agilent DD2 500 spectrometers. The solid samples were digested before the measurement using DMSO- $d_{6}(0.5 \mathrm{~mL})$ and $\mathrm{DCl} / \mathrm{D}_{2} \mathrm{O}(35 \mathrm{wt} \%$, one drop, less than $0.1 \mathrm{~mL}$ ) as solvents. The data were processed with the MestReNova (v14.2.0) software. Data were referenced to the residual proton signal of DMSO and chemical shifts are given relative to tetramethylsilane.

Thermal analysis. Differential scanning calorimetry measurements (DSC) were performed on a DSC 25 from TA Instruments under a constant nitrogen flow $\left(50 \mathrm{~mL} \mathrm{~min}^{-1}\right)$. Before the measurement, the samples were ground and placed in a hermitically sealed aluminium crucible and a hole was pinched into the lid of the sealed crucible. Simultaneous thermogravimetric analysis / differential scanning calorimetry (TGA/DSC) measurements were conducted on a STA 504 instrument or SDT 650 from TA Instruments under a constant argon flow $\left(4 \mathrm{~L} \mathrm{~h}^{-1}\right)$ for STA 504 or a nitrogen flow $\left(100 \mathrm{~mL} \mathrm{~min}^{-1}\right)$ for SDT 650 on powdered samples. Data were processed and evaluated using the TRIOS (v5.1.0.46403) software from TA instruments. The melting temperatures $\left(T_{\mathrm{m}}\right)$ are determined as the peak offset, the glass transition temperatures $\left(T_{\mathrm{g}}\right)$ as the peak onset, whereas all other derived temperatures are defined as the peak temperature. The enthalpies are determined from the integral of the corresponding signal.

Isothermal gas physisorption. Experiments were performed with a Quantachrome iQ MP porosimeter. Sample quantities of about $100 \mathrm{mg}$ (for glasses) and at least $50 \mathrm{mg}$ 
(for all others) were used for the experiments. Prior to the first measurement the ground samples were degassed under dynamic vacuum $\left(p \approx 10^{-5} \mathrm{kPa}\right)$ at $200{ }^{\circ} \mathrm{C}$ for $2 \mathrm{~h}$. Gas sorption isotherms were measured with $\mathrm{N}_{2}(77 \mathrm{~K}), \mathrm{CO}_{2}(195 \mathrm{~K}$ and $273 \mathrm{~K})$ and $n$ butane $(273 \mathrm{~K})$, propane and propylene (293 K). Between measurements, samples were degassed under dynamic vacuum $\left(p \approx 10^{-5} \mathrm{kPa}\right)$ at ambient temperature for approximately $3 \mathrm{~h}$. After adsorption measurements with $n$-butane, sample were again heated to $200^{\circ} \mathrm{C}$ for 30 min under dynamic vacuum $\left(p \approx 10^{-5} \mathrm{kPa}\right)$.

X-ray total scattering. X-ray total scattering data for ZIF-4, aTZIF-4, zniTZIF-4, agZIF4, ZIF-zni, agZIF-zni and $a_{g}$ ZIF-62 were collected at beamline I15-1 of Diamond Light Source (DLS, UK) using a monochromatic X-ray beam $(\lambda=0.161669 \AA$, $76.7 \mathrm{keV})$. Samples were finely ground before loading into $1.5 \mathrm{~mm}$ (outer diameter) borosilicate capillaries. X-ray total scattering data for TIF-4 and $a_{g}$ TIF-4 were collected at beamline P02.1 at Deutsches Elektronen-Synchrotron (DESY, Germany) using a monochromatic X-ray beam $(\lambda=0.20734 \AA$, $60 \mathrm{keV})$. The samples were placed in a $1 \mathrm{~mm}$ (outer diameter) quartz glass capillary. For all datasets, background subtraction was performed with scattering data collected from an empty capillary. Background subtraction, multiple, container and Compton scattering, as well as for absorption were done with the GudrunX program. ${ }^{95}$ The normalized reciprocal space data $(S(Q)$, see Fig. S40 for corresponding $Q_{\max }$ values) were Fourier transformed to yield the X-ray pair distribution functions (XPDFs) in the form of $D(r) .{ }^{68,96}$

\section{References}

1. Yaghi, O. M. et al. Reticular synthesis and the design of new materials. Nature 423, 705-714 (2003).

2. Tranchemontagne, D. J., Mendoza-Cortés, J. L., O’Keeffe, M. \& Yaghi, O. M. Secondary building units, nets and bonding in the chemistry of metal-organic frameworks. Chem. Soc. Rev. 38, 1257 (2009).

3. Stock, N. \& Biswas, S. Synthesis of metal-organic frameworks (MOFs): Routes to various MOF topologies, morphologies, and composites. Chem. Rev. 112, 933-969 (2012).

4. Yuan, S. et al. Stable Metal-Organic Frameworks: Design, Synthesis, and 
Applications. Adv. Mater. 30, 1-35 (2018).

5. Lin, R. B., Xiang, S., Xing, H., Zhou, W. \& Chen, B. Exploration of porous metal-organic frameworks for gas separation and purification. Coord. Chem. Rev. 378, 87-103 (2019).

6. Kreno, L. E. et al. Metal-Organic Framework Materials as Chemical Sensors. Chem. Rev. 112, 1105-1125 (2012).

7. Lin, Y., Kong, C., Zhang, Q. \& Chen, L. Metal-Organic Frameworks for Carbon Dioxide Capture and Methane Storage. Adv. Energy Mater. 7, 1601296 (2016).

8. Furukawa, H., Cordova, K. E., O'Keeffe, M. \& Yaghi, O. M. The Chemistry and Applications of Metal-Organic Frameworks. Science 341, 974-986 (2013).

9. Horcajada, P. et al. Metal-Organic Frameworks in Biomedicine. Chem. Rev. 112, 1232-1268 (2012).

10. Baumann, A. E., Burns, D. A., Liu, B. \& Thoi, V. S. Metal-organic framework functionalization and design strategies for advanced electrochemical energy storage devices. Commun. Chem. 2, 86 (2019).

11. Stavila, V., Talin, A. A. \& Allendorf, M. D. MOF-based electronic and optoelectronic devices. Chem. Soc. Rev. 43, 5994-6010 (2014).

12. Bennett, T. D., Coudert, F. X., James, S. L. \& Cooper, A. I. The changing state of porous materials. Nat. Mater. (2021). doi:10.1038/s41563-021-00957-w

13. Pallach, R. et al. Frustrated flexibility in metal-organic frameworks. Nat. Commun. 12, 1-12 (2021).

14. Bennett, T. D. \& Cheetham, A. K. Amorphous metal-organic frameworks. Acc. Chem. Res. 47, 1555-1562 (2014).

15. Fonseca, J., Gong, T., Jiao, L. \& Jiang, H. L. Metal-organic frameworks (MOFs) beyond crystallinity: amorphous MOFs, MOF liquids and MOF glasses. J. Mater. Chem. A 9, 10562-10611 (2021).

16. Bennett, T. D. \& Horike, S. Liquid, glass and amorphous solid states of coordination polymers and metal-organic frameworks. Nat. Rev. Mater. 3, 431-440 (2018).

17. Simonov, A. \& Goodwin, A. L. Designing disorder into crystalline materials. Nat. Rev. Chem. 4, 657-673 (2020).

18. Cheetham, A. K., Bennett, T. D., Coudert, F. X. \& Goodwin, A. L. Defects and disorder in metal organic frameworks. Dalt. Trans. 45, 4113-4126 (2016). 
19. Sapnik, A. F. et al. Mixed hierarchical local structure in a disordered metalorganic framework. Nat. Commun. 12, 1-12 (2021).

20. Jiang, G. et al. Glassy Metal-Organic-Framework-Based Quasi-Solid-State Electrolyte for High-Performance Lithium-Metal Batteries. Adv. Funct. Mater. 2104300 (2021). doi:10.1002/adfm.202104300

21. Bennett, T. D. et al. Hybrid glasses from strong and fragile metal-organic framework liquids. Nat. Commun. 6, 8079 (2015).

22. Tao, H., Bennett, T. D. \& Yue, Y. Melt-Quenched Hybrid Glasses from MetalOrganic Frameworks. Adv. Mater. 29, 1601705 (2017).

23. Bennett, T. D. et al. Melt-Quenched Glasses of Metal-Organic Frameworks. J. Am. Chem. Soc. 138, 3484-3492 (2016).

24. Horike, S., Nagarkar, S. S., Ogawa, T. \& Kitagawa, S. A New Dimension for Coordination Polymers and Metal-Organic Frameworks: Towards Functional Glasses and Liquids. Angew. Chem. Int. Ed. 59, 6652-6664 (2020).

25. Horike, S., Ma, N., Fan, Z., Kosasang, S. \& Smedskjaer, M. M. Mechanics, Ionics, and Optics of Metal-Organic Framework and Coordination Polymer Glasses. Nano Lett. (2021). doi:10.1021/acs.nanolett.1c01594

26. Tanaka, K. et al. High Li-lon Conductivity in Li\{ $(\mathrm{N}(\mathrm{SO} 2 \mathrm{~F}) 2\}(\mathrm{NCCH} 2 \mathrm{CH} 2 \mathrm{CN}) 2$ Molecular Crystal. Nano Lett. 20, 8200-8204 (2020).

27. Ogawa, T. et al. Coordination polymer glass from a protic ionic liquid: proton conductivity and mechanical properties as an electrolyte. Chem. Sci.11, 51755181 (2020).

28. Wang, Y. et al. A MOF Glass Membrane for Gas Separation. Angew. Chem. Int. Ed. 59, 4365-4369 (2020).

29. Li, J. et al. Coordination Polymer Glasses with Lava and Healing Ability for High-Performance Gas Sieving. Angew. Chem. Int. Ed. 60, 21304-21309 (2021).

30. Frentzel-Beyme, L., Kloss, M., Kolodzeiski, P., Pallach, R. \& Henke, S. Meltable Mixed-Linker Zeolitic Imidazolate Frameworks and Their Microporous Glasses - From Melting Point Engineering to Selective Hydrocarbon Sorption. J. Am. Chem. Soc. 141, 12362-12371 (2019).

31. Tuffnell, J. M. et al. Novel metal-organic framework materials: Blends, liquids, glasses and crystal-glass composites. Chem. Commun. 55, 8705-8715 (2019). 
32. Madsen, R. S. K. et al. Ultrahigh-field 67Zn NMR reveals short-range disorder in zeolitic imidazolate framework glasses. Science 367, 1473-1476 (2020).

33. Freund, R. et al. 25 Years of Reticular Chemistry. Angew. Chem. Int. Ed. 60, 23946-23974 (2021).

34. Park, K. S. et al. Exceptional chemical and thermal stability of zeolitic imidazolate frameworks. PNAS 103, 10186-10191 (2006).

35. Tian, Y. Q. et al. Design and generation of extended zeolitic metal-organic frameworks (ZMOFs): Synthesis and crystal structures of zinc(II) imidazolate polymers with zeolitic topologies. Chem. Eur. J. 13, 4146-4154 (2007).

36. Noh, K., Lee, J. \& Kim, J. Compositions and Structures of Zeolitic Imidazolate Frameworks. Isr. J. Chem. 58, 1075-1088 (2018).

37. Ríos Gómez, M. L., Lampronti, G. I., Yang, Y., Mauro, J. C. \& Bennett, T. D. Relating structural disorder and melting in complex mixed ligand zeolitic imidazolate framework glasses. Dalt. Trans. 49, 850-857 (2020).

38. Hou, J. et al. Halogenated Metal-Organic Framework Glasses and Liquids. J. Am. Chem. Soc. 142, 3880-3890 (2020).

39. Zhou, C. et al. Polymorph formation for a zeolitic imidazolate framework composition - Zn(Im) 2. Microporous Mesoporous Mater. 265, 57-62 (2018).

40. Longley, L. et al. Flux melting of metal-organic frameworks. Chem. Sci. 10, 3592-3601 (2019).

41. Bumstead, A. M. et al. Investigating the melting behaviour of polymorphic zeolitic imidazolate frameworks. CrystEngComm 22, 3627-3637 (2020).

42. Zhou, C. et al. Metal-organic framework glasses with permanent accessible porosity. Nat. Commun. 9, 5042 (2018).

43. Böhme, U. et al. Ethene/ethane and propene/propane separation via the olefin and paraffin selective metal-organic framework adsorbents CPO-27 and ZIF-8. Langmuir 29, 8592-8600 (2013).

44. Yang, J. et al. Principles of Designing Extra-Large Pore Openings and Cages in Zeolitic Imidazolate Frameworks. J. Am. Chem. Soc. 139, 6448-6455 (2017).

45. Banerjee, R. et al. High-Throughput Synthesis of Zeolitic Imidazolate Frameworks and Application to CO2 Capture. Science 319, 939-943 (2008).

46. Li, K. et al. Zeolitic Imidazolate Frameworks for Kinetic Separation of Propane 
and Propene. J. Am. Chem. Soc. 131, 10368-10369 (2009).

47. Hartmann, M., Böhme, U., Hovestadt, M. \& Paula, C. Adsorptive Separation of Olefin/Paraffin Mixtures with ZIF-4. Langmuir 31, 12382-12389 (2015).

48. Bennett, T. D. et al. Structure and properties of an amorphous metal-organic framework. Phys. Rev. Lett. 104, 2-5 (2010).

49. Thornton, A. W. et al. Porosity in metal-organic framework glasses. Chem. Commun. 52, 3750-3753 (2016).

50. Gaillac, R. et al. Liquid Metal-Organic Frameworks. Nat. Mater. 16, 1149-1154 (2017).

51. Gaillac, R., Pullumbi, P., Bennett, T. D. \& Coudert, F. X. Structure of MetalOrganic Framework Glasses by Ab Initio Molecular Dynamics. Chem. Mater. 32, 8004-8011 (2020).

52. Qiao, A. et al. A metal-organic framework with ultrahigh glass-forming ability. Sci. Adv. 4, eaao68279 (2018).

53. Zhou, C. et al. Metal-organic framework glasses with permanent accessible porosity. Nat. Commun. 9, 5042 (2018).

54. Gidley, D. W., Peng, H. G. \& Vallery, R. S. Positron annihilation as a method to characterize porous materials. Annu. Rev. Mater. Res. 36, 49-79 (2006).

55. Sing, K. S. W. Reporting physisorption data for gas/solid systems with special reference to the determination of surface area and porosity (Recommendations 1984). Pure Appl. Chem. 57, 603-619 (1985).

56. Thommes, M. et al. Physisorption of gases, with special reference to the evaluation of surface area and pore size distribution (IUPAC Technical Report). Pure Appl. Chem. 87, 1051-1069 (2015).

57. Cychosz, K. A. \& Thommes, M. Progress in the Physisorption Characterization of Nanoporous Gas Storage Materials. Engineering 4, 559-566 (2018).

58. Islamoglu, T. et al. Are you using the right probe molecules for assessing the textural properties of metal-organic frameworks? J. Mater. Chem. A (2022). doi:10.1039/D1TA08021K

59. Decker, G. E. \& Bloch, E. D. Using Helium Pycnometry to Study the Apparent Densities of Metal-Organic Frameworks. ACS Appl. Mater. Interfaces acsami.1c07304 (2021). doi:10.1021/acsami.1c07304

60. Stepniewska, M., Østergaard, M. B., Zhou, C. \& Yue, Y. Towards large-size 
bulk ZIF-62 glasses via optimizing the melting conditions. J. Non. Cryst. Solids 530, 119806 (2020).

61. Qiao, A. et al. Deformation mechanism of a metal-organic framework glass under indentation. Phys. Chem. Chem. Phys. 23, 16923-16931 (2021).

62. Pawley, G. S. Unit-cell refinement from powder diffraction scans. J. Appl. Crystallogr. 14, 357-361 (1981).

63. Phan, A. et al. Synthesis, structure, and carbon dioxide capture properties of zeolitic imidazolate frameworks. Acc. Chem. Res. 43, 58-67 (2010).

64. Wu, T., Bu, X., Zhang, J. \& Feng, P. New zeolitic imidazolate frameworks: From unprecedented assembly of cubic clusters to ordered cooperative organization of complementary ligands. Chem. Mater. 20, 7377-7382 (2008).

65. Lehnert, R. \& Seel, F. Darstellung und Kristallstruktur des Mangan(II)- und Zink(II)-Derivates des Imidazols. ZAAC 464, 187-194 (1980).

66. Bennett, T. D. et al. Thermal amorphization of zeolitic imidazolate frameworks. Angew. Chem. Int. Ed. 50, 3067-3071 (2011).

67. Schröder, C. A., Baburin, I. A., van Wüllen, L., Wiebcke, M. \& Leoni, S. Subtle polymorphism of zinc imidazolate frameworks: temperature-dependent ground states in the energy landscape revealed by experiment and theory. CrystEngComm 15, 4036-4040 (2013).

68. Keen, D. A. A comparison of various commonly used correlation functions for describing total scattering. J. Appl. Crystallogr. 34, 172-177 (2001).

69. Elliott, S. R. Medium-range structural order in covalent amorphous solids. Nature 354, 445-452 (1991).

70. Elliott, S. R. Origin of the first sharp diffraction peak in the structure factor of covalent glasses. Phys. Rev. Lett. 67, 711-714 (1991).

71. Salmon, P. S. Real space manifestation of the first sharp diffraction peak in the structure factor of liquid and glassy materials. Proc. R. Soc. London. Ser. A Math. Phys. Sci. 445, 351-365 (1994).

72. Ramesh Rao, N. et al. Structural correlations in GexSe1-x glasses - a neutron diffraction study. J. Non. Cryst. Solids 240, 221-231 (1998).

73. Lucovsky, G. \& Phillips, J. C. Symmetry determined medium range order (MRO) contributions to the first sharp diffraction peak (FSDP) in non-crystalline oxide and chalcogenide glasses. Phys. Status Solidi Basic Res. 246, 1806- 
$1812(2009)$.

74. Breck, D. W. Zeolite molecular sieves : structure, chemistry, and use. (Wiley, 1973).

75. Marsh, H. \& Brand, B. The Characterization of Microporous Carbons by Means of the Dubinin-Radushkevich Equation. J. Colloid Interface Sci. 33, 101-116 (1970).

76. Klank, D., Blum, C. \& Schneider, D. Adsorptionsstudien mit CO 2 - Flüssigkeit oder Trockeneis? Chemie Ing. Tech. 92, 1871-1872 (2020).

77. Ongari, D. et al. Accurate characterization of the pore volume in microporous crystalline materials. Langmuir 33, 14529-14538 (2017).

78. Brunauer, S., Emmett, P. H. \& Teller, E. Adsorption of Gases in Multimolecular Layers. J. Am. Chem. Soc. 60, 309-319 (1938).

79. Zachariasen, W. H. THE ATOMIC ARRANGEMENT IN GLASS. J. Am. Chem. Soc. 54, 3841-3851 (1932).

80. Lastoskie, C., Gubbins, K. E. \& Quirke, N. Pore size distribution analysis of microporous carbons: a density functional theory approach. J. Phys. Chem. 97, 4786-4796 (1993).

81. Willems, T. F., Rycroft, C. H., Kazi, M., Meza, J. C. \& Haranczyk, M. Algorithms and tools for high-throughput geometry-based analysis of crystalline porous materials. Microporous Mesoporous Mater. 149, 134-141 (2012).

82. Kikkinides, E. S., Monson, P. A. \& Valiullin, R. Sorption Isotherm Reconstruction and Extraction of Pore Size Distributions for Serially Connected Pore Model (SCPM) Structures Employing Algorithmic and Statistical Models. J. Phys. Chem. C 124, 21591-21607 (2020).

83. Nguyen, H. G. T., Horn, J. C., Bleakney, M., Siderius, D. W. \& Espinal, L. Understanding material characteristics through signature traits from helium pycnometry. Langmuir 35, 2115-2122 (2019).

84. To, T. et al. Fracture toughness of a metal-organic framework glass. Nat. Commun. 11, 2593 (2020).

85. GESTIS-Stoffdatenbank - Propane. Available at: https://gestis.dguv.de/data?name=010020.

86. GESTIS-Stoffdatenbank - Propylene. Available at: https://gestis.dguv.de/data?name=010100. 
87. GESTIS-Stoffdatenbank - n-butane. Available at:

https://gestis.dguv.de/data?name=010030.

88. Enke, D., Janowski, F. \& Schwieger, W. Porous glasses in the 21st century-a short review. Microporous Mesoporous Mater. 60, 19-30 (2003).

89. Widmer, R. N. et al. Pressure promoted low-temperature melting of metalorganic frameworks. Nat. Mater. 18, 370-376 (2019).

90. Mc Keown, N. B. \& Budd, P. M. Polymers of intrinsic microporosity (PIMs): Organic materials for membrane separations, heterogeneous catalysis and hydrogen storage. Chem. Soc. Rev. 35, 675-683 (2006).

91. Das, S., Heasman, P., Ben, T. \& Qiu, S. Porous Organic Materials: Strategic Design and Structure-Function Correlation. Chem. Rev. 117, 1515-1563 (2017).

92. Park, H. B. et al. Polymers with cavities tuned for fast selective transport of small molecules and ions. Science 318, 254-258 (2007).

93. Butler, B. J. et al. An Efficient Polymer Molecular Sieve for Membrane Gas Separations. Science 303-307 (2013).

94. Coelho, A. A. TOPAS and TOPAS-Academic: An optimization program integrating computer algebra and crystallographic objects written in C++: An. J. Appl. Crystallogr. 51, 210-218 (2018).

95. Soper, A. K. GudrunN and GudrunX : programs for correcting raw neutron and X-ray diffraction data to differential scattering cross section. Rutherford Applet. Lab. Tech. Reports (2011).

96. Soper, A. K. \& Barney, E. R. Extracting the pair distribution function from whitebeam X-ray total scattering data. J. Appl. Crystallogr. 44, 714-726 (2011).

\section{Acknowledgement}

This project received funding from TU Dortmund, Deutsche Forschungsgemeinschaft within the Priority Programme SPP1928 COORNETs and project 447344931 (HE 7628/7-1) and was supported by an Exploration Grant of Boehringer Ingelheim Foundation (BIS). P.K. acknowledges the Fonds der Chemischen Industrie for awarding a Kekulé-Fellowship. The research leading to this result has been supported by the project CALIPSOplus under the Grant Agreement 730872 from the EU Framework Programme for Research and Innovation HORIZON 2020. We thank 
Diamond Light Source (DLS) for access to beamline I15-1 (CY21604-2) that contributed to the results presented here. Beamline scientists Thomas Forrest and Philip Chater are acknowledged for their support with the X-ray total scattering experiments at DLS. We thank Jianbo Song and Roman Pallach for their helped with collecting these data. We acknowledge DESY (Hamburg, Germany), a member of the Helmholtz Association HGF, for the provision of experimental facilities. Parts of this research were carried out at PETRA III on beamline P02.1 and we thank Alba San Jose Mendez and Volodymyr Baran for assistance in collecting X-ray total scattering data. Beamtime was allocated for proposal I-20210316. Athanasios Koutsianos and Roman Pallach are acknowledged for their help by conducting these experiments. Volker Brandt is acknowledged for collection of SEM images.

\section{Author contribution}

L.F.-B., P.K. and J.-B.W. synthesized the materials and performed and analyzed XRPD, FTIR spectroscopy, NMR spectroscopy and thermal analysis experiments. L.FB. and P.K collected and analyzed X-ray total scattering data. L.F.-B. collected and analyzed gas physisorption data. All authors contributed to discussing the data. L.F.B. and S.H. wrote the manuscript. 